\title{
A Quarter of a Century with AIDS
}

\author{
C. Rodríguez-Cerdeira, ${ }^{*}$, M.J. Cruces ${ }^{2}$ and J.A. Taboada ${ }^{2}$ \\ ${ }^{I}$ Department of Dermatology, CHUVI \& Universty of Vigo, Vigo, Spain \\ ${ }^{2}$ Dirección Xeral de Saúde Pública, Xunta de Galicia, Santiago de Compostela, Spain
}

\begin{abstract}
In Northwestern Spain (NWS), the annual incidence of AIDS diagnoses increased from 1984 (when the first case was diagnosed) until 1996. However, since 1996, this incidence has reduced considerably, including a notable $40 \%$ reduction between 1997 and 1998. The Galician Register of AIDS supplies information on the evolution of AIDS pathology in NWS. This report compiles data on patients who were diagnosed with AIDS in NWS between 1984 and 2008. From 1981, when the first case of AIDS was described, until December 31, 2008, a total of 3,766 AIDS cases were registered in NWS. Of these, 2,085 cases (55.4\%) resulted in death. Examining data from individual provinces revealed that the highest number of cases was in A Coruña (1,548 cases) followed by Pontevedra (1,485 cases).

For almost half of the new cases of AIDS diagnosed between 2003 and 2008 (44\%), less than six months passed between the diagnosis of infection and manifestations of the disease. Thus, the number of patients that do not receive early diagnosis of HIV infection has remained high.

With regard to the transmission mechanism, 64\% of the cases occurring during these years resulted from needle-sharing among injected drug users (IDUs). Unprotected heterosexual and homosexual practices were responsible for $20 \%$ and $17 \%$ of the cases, respectively.
\end{abstract}

Keywords: AIDS, HIV, Northwestern Spain.

\section{INTRODUCTION}

AIDS' so-called quiet pandemic saw its "symbolic eradication" at the First International Conference on AIDS (1985). Important achievements were reviewed at this meeting, such as the discovery of the virus, its transmission routes, the related clinical picture and early diagnostic techniques. Moreover, the magnitude of the problem was considered. This knowledge facilitated the construction of a realistic vision of HIV/AIDS. In addition, scientists and professionals were alerted to the importance of this disease and formed a united front against it, which continues to this day. In 1988, the Autonomous Plan for the prevention and control of AIDS was created for NWS, following the creation of the Commission for control and follow-up. Later, "The Galician Service of Information on HIV" (SIGIVIH) was founded to complement and improve recorded information from previous systems and equate it to present infection data [1].

The first diagnosis of AIDS in NWS occurred in 1984 in an IDU male. Since then, the number of cases has increased, and new transmission routes have been reported. In 1985 appeared the first cases in a patient that had received blood derivates and in homosexual and bisexual males, at the same time the incidence of new cases among IDUs continued to increase. Although the proportion of cases corresponding to

*Address correspondence to this author at the Department of Dermatology, CHUVI \& Universty of Vigo, Vigo, Spain; Tel: 0034600536114; Fax: 0034986276416; E-mails: aristoteles_cerdeira@yahoo.es,

carmen.rodriguez.cerdeira@sergas.es each transmission category has varied over the years, until recently, IDUs were the prevailing routes of infection.

However, the AIDS epidemic in NWS has evolved in a favorable way. By the beginning of the twenty-first century, the situation was less grave than in the two previous decades, although, as is reflected in successive plans, HIV infection still constitutes one of the main public health problems in our community.

Since 2005, the annual number of new AIDS cases in NWS has been fewer than 100 cases per year, continuing the trend seen at the end of the twentieth century. The number of cases has since stabilized at fewer than 50 cases per million inhabitants which was one of the objectives outlined in the 2006 to 2010 Galician Health Plan [1, 2].

Recent years have seen an increase in infections caused by unsafe sexual practices associated with heterosexual transmission. Such activities are now the most frequent transmission route. An additional problem in recent years is immigrants, due to their social and economic vulnerability. Notably, the majority of women who practice prostitution in our country are immigrants [3].

\section{MATERIALS AND METHODS}

We studied the Galician AIDS population from an epidemiological point of view over a period of 25 years (1984 to 2008) with the following aims:

1. Focus the health system toward both the diagnosed and undiagnosed HIV populations. 
2. Characterize and quantify the population of patients who are diagnosed late after infection, and then identify consequences that arise from this late diagnosis.

3. Identify the social, medical and structural barriers preventing early HIV diagnosis and control, and propose solutions accordingly.

4. Promote a joint effort from all angles (specialists, patients, NGO, health authorities, the mass media and the general public) to propel the fight against HIV/AIDS at all levels.

\section{STATISTICAL ANALYSIS}

\section{Design}

We highlight two studies: first, a retrospective, observational descriptive study that collected AIDS cases in NWS from January 1984 through December 2008; and second, a transverse observational descriptive sub-study that collected AIDS cases in NWS from 2002 to 2005 to compare the dates for starting the SIGIVIH program. We collected all AIDS cases according to the criteria given by the CDC in 1993. The sample population obtained from these cases fell within the inclusion-exclusion criteria. We included all patients whose registration forms, prepared by the National Registry of AIDS in NWS, were duly filled in by the physician identifying them as an AIDS case. Incomplete or doubtful registration forms were redone.

\section{Variables Collected}

All rates cited in this report take monthly interim populations into account as calculated by the Epidemiology Service and the "Dirección General de Salud Pública" (Public Health Service) from the interpolation of census data from 1981 to 1998 and refer to the first of June of each year from 1994 to 1998 . The populations from 1999 to 2008 are considered according to the corresponding censuses.

Demographic variables included age, sex, province (A Coruña, Lugo, Ourense, Pontevedra), place of birth (Spain,
Europe, South America, Sub-Saharan Africa), date of HIV+ diagnosis (via communication from the laboratory which analyzed the sample), date of AIDS diagnosis, offspring of carrier mothers, IDUs, type of sexual relationships (heterosexual, bisexual or homosexual), types of disease that were indicative of AIDS, infection route and death.

\section{Analysis of Dates}

A descriptive analysis was performed on all variables collected in the study. Analysis included both qualitative (frequencies and percentages) and quantitative (means, frequencies and accumulated frequencies) measures.

To test for the association between variables, the Chisquared test was used to compare sample proportions.

Other frequencies measured included the annual incidence and the accumulated incidence. The annual incidence was calculated by determining the number of new cases per year per million inhabitants. The accumulated incidence or risk was defined as the number of new cases per year per million inhabitants divided by the population at risk at the beginning of the year.

\section{RESULTS}

\section{AIDS Cases in NWS by Region}

The accumulated number of cases of AIDS in NWS, including living and deceased patients, through December, 31,2008 , was 3,766 . The province of A Coruña had the highest number of cases $(1,548$, compared to 1,485 in Pontevedra, 423 in Ourense and 310 in Lugo). However, calculating the accumulated rates per million inhabitants from 1984 to 2008 revealed that the region with the highest rate was Pontevedra, with 1,565 cases per million residents (compared to 1,342 in A Coruña and 1,168 in Ourense). Lugo had the lowest accumulated rate with 798 cases per million inhabitants over the 25-year period (Fig. 1). Death occurred in $55 \%$ of the 3,766 . However, we observed a rise in incidence and a reduction in mortality in recent years (Figs. 1, 2).

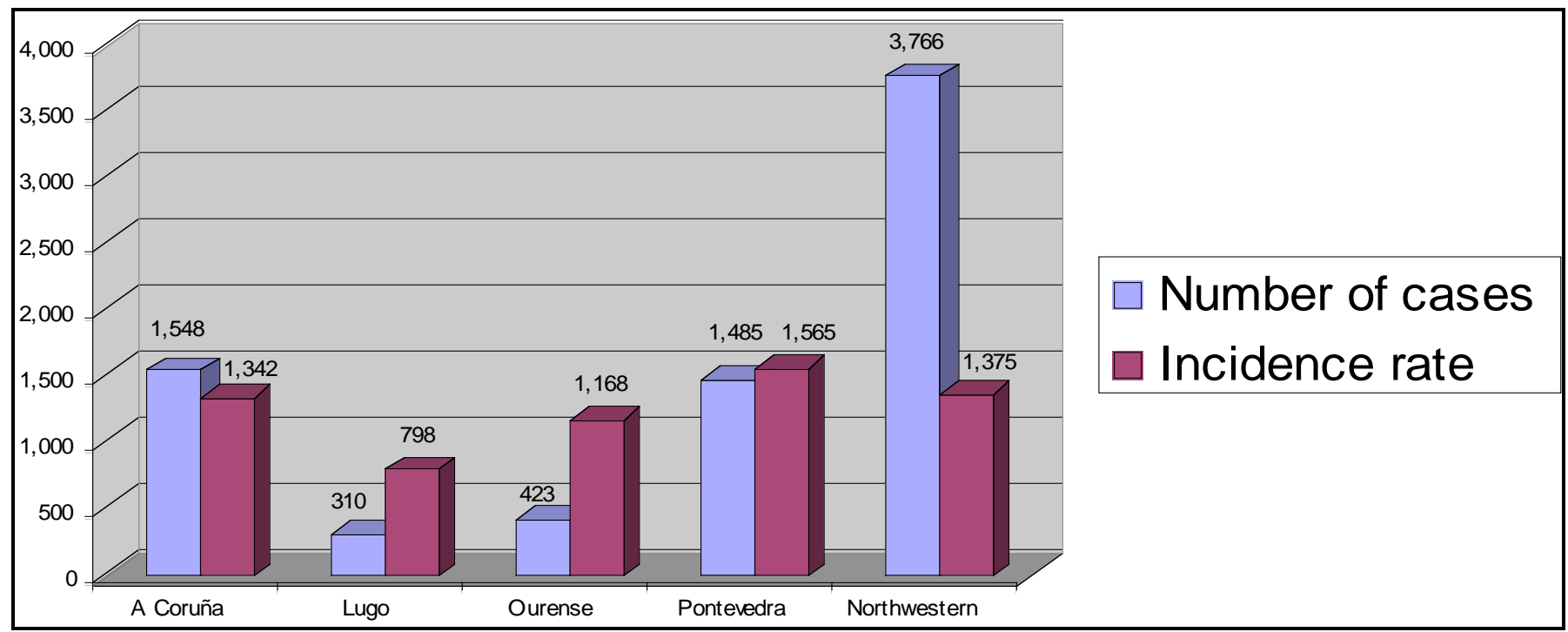

Fig. (1). Accumulated number of cases of AIDS and cumulative incidence rate in different provinces of Northwestern of Spain. 


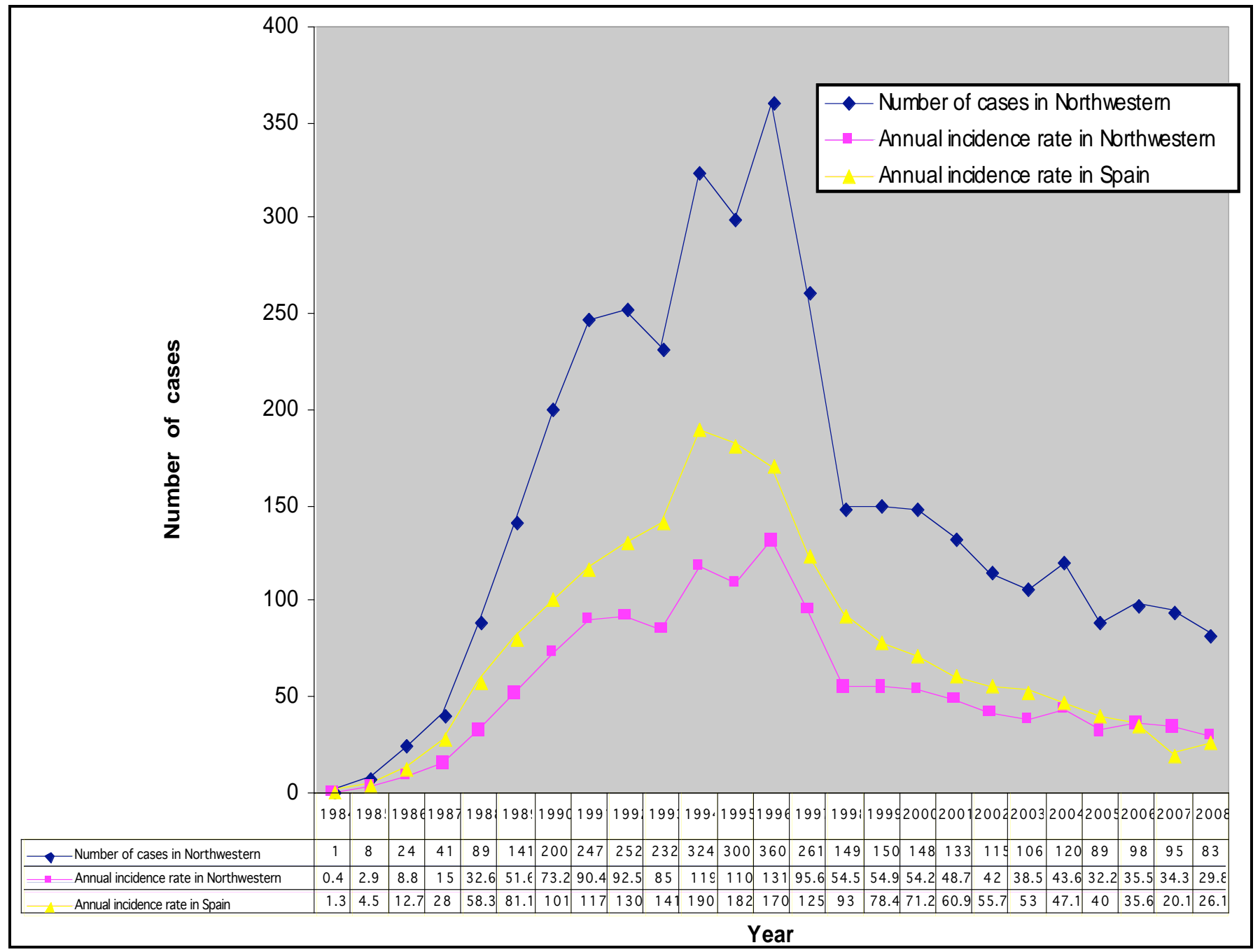

Fig. (2). Annual incidence rate of AIDS in Northwestern of Spain-Spain.

\section{AIDS Cases by Sex}

The majority (77.3\%) of AIDS cases occurred in males. The sex ratio (men to women) decreased from the end of the 1980s until the mid-1990s. Since 1996, the behavior has been more irregular, although the ratio reached 3.4 to 1 .

\section{AIDS Cases by Age}

With regard to age, it should be pointed out that AIDS fundamentally affects young adults. Patients between 25 and 39 years of age accounted for $69 \%$ of all cases. When the age intervals were altered to include patients diagnosed between 20 and 44 years of age, this figure rose to $86 \%$.

The age of diagnosis has shown a sustained upward trend. Between 2002 and 2008, the mean rose from 38 to 41 years old, without significant differences between the sexes. The register includes 66 cases of AIDS in people over 65 years of age, $80 \%$ of which were male.

\section{AIDS Cases by Birth Cohort}

With respect to the date of birth cohorts, AIDS has had the largest impact on patients born between 1960 and 1964, although in the cases declared from 1995 onwards, it is seen that patients born in the following quinquennial have similar results to the anterior. Overall, patients born between 1960 and 1969 represented the majority of all cases registered by December 31, 2008 (56\%).

As for pregnant women, we have no precise data on all of the patients following antiretroviral therapy. Until 1997 there were 13 cases of HIV infection by maternal transmission. In 2003 we registered 1 case. From this year there was not any transmission of HIV infection in this way. Nevertheless, a seroepidemiological survey to calculate the prevalence of anti-HIV-1 and -2 antibodies, in newborns, per year was performed in NWS from 1991 onwards, first in collaboration with the Hospital La Fe (Valencia) within the framework approved by the US Institute of Child Health and Human Development and the Theobald Smith Research Institute. This work was continued in a study using an anonymous method with unrelated blood samples originally obtained from mothers and their children for use in detecting metabolic diseases, which occurred in $99 \%$ of the cases in the NWS general population. This study shows a prevalence rate around of 1 per thousand in women who gave birth. 




Fig. (3). Number of cases of AIDS by transmission category in women in Northwestern of Spain.

\section{AIDS Cases by Transmission Risk}

The most frequent transmission route of AIDS in Galicia has been IDUs, which corresponded to $43.4 \%$ of the diagnoses in 2008. Heterosexual transmission was the second most frequent route that year, corresponding to $30.1 \%$ of cases. This value remained stable over the last four years in men, although it showed a slight decrease in women. A general decrease was observed in cases in IDUs, both male and female, beginning in 1996 (Figs. 3, 4).
Within the category of men who had sexual relationships with other men, the evolution was more regular, with an apparent stabilization in the later years of the study. Taking recent data from other Spanish communities into account, we may experience a possible increase in this group over the following years.

Men and women infected by heterosexual transmission were analyzed separately. In men, there was an evolution similar to that observed in the IDU group. In women, the

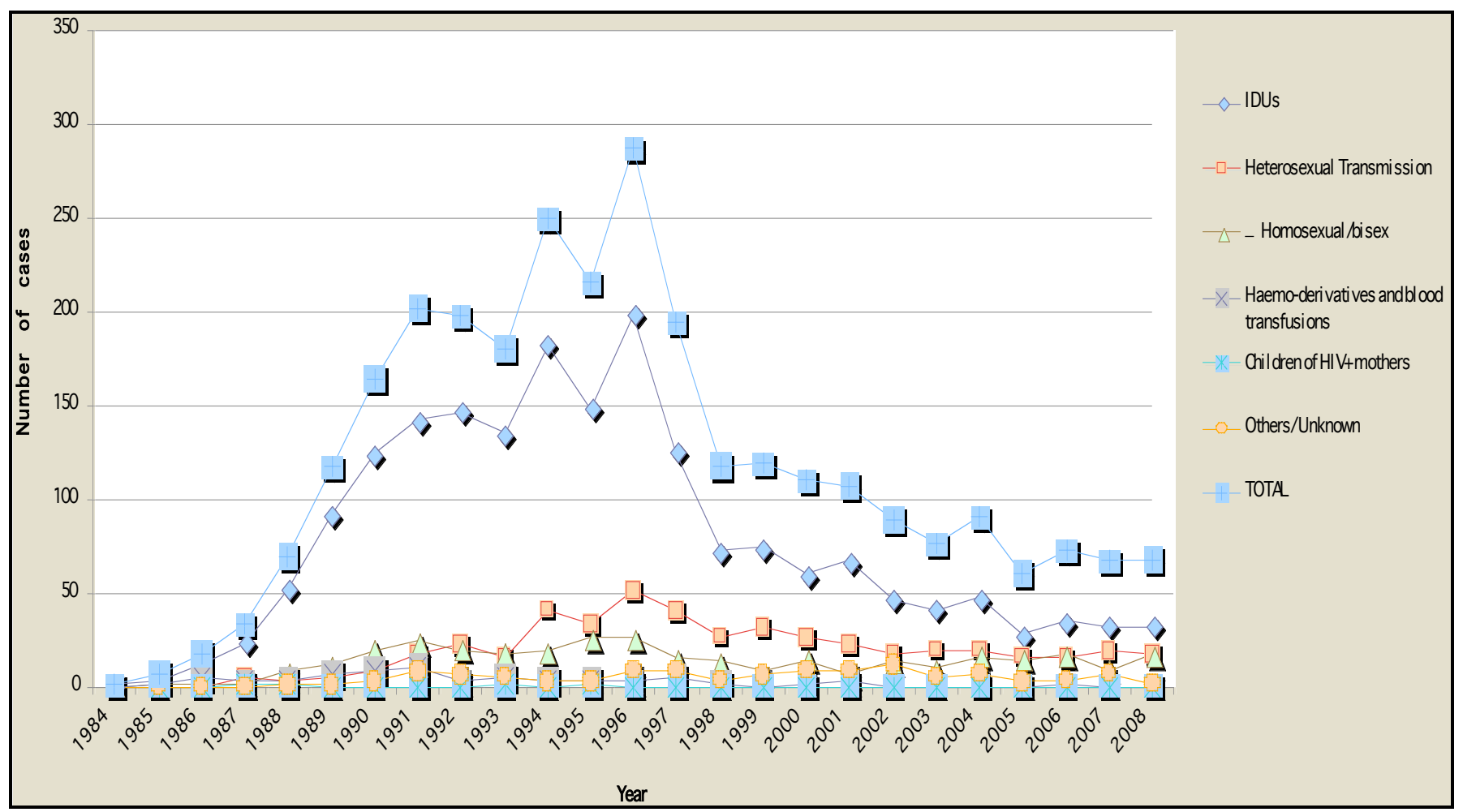

Fig. (4). Number of cases of AIDS by transmission route in men in Northwestern of Spain. 
number of cases resulting from heterosexual transmission has been stable since 1998 .

Although IDUs was the most common mode of transmission for both sexes over the 25-year study period, during the period between 2003 and 2008, it represented $50 \%$ in men and $39 \%$ in women. We should highlight that between 2003 and 2008, heterosexual transmission accounted for $25 \%$ and $48 \%$ of the AIDS cases diagnosed in man and women, respectively. The fact that, for men, transmission via unsafe homosexual sexual practices accounted for $19 \%$ of the cases of AIDS between the years 2003 and 2008 should be considered separately (Figs. 3, 4).

\section{The Time Between a positive HIV Test and an AIDS Diagnosis with AIDS-Defining Illnesses}

Between the years 2003 and 2008, almost half of new patients with AIDS (44\%) had learned that they were HIV+ less than 6 months earlier. Thirty-one percent of patients presented with an immunosuppression of less than 200 cells $/ \mu 1$ when they were diagnosed, and $17 \%$ had an immunosuppression between 200 and $250 \mathrm{CD} 4+$ cells $/ \mu \mathrm{l}$, which supposes that half of the diagnosed patients were already susceptible to being under antiretroviral treatment when they were diagnosed, taking into account the present criteria regarding the start of antiretroviral therapy.

We did not observe differences by genre. The evolution of time intervals between the diagnosis of AIDS are shown in Fig. (5). Taking into account the different transmission categories, late diagnosis over the five-year period was greater in those infected through unprotected heterosexual relationships than those infected by IDUs $(37 \%)$ or MSM $(22 \%)$.

Finally, with respect to the diseases indicative of AIDS, we should comment on the period between 1994 to 2008. In 1994, the definition of AIDS was added to the epidemiological vigilance register, adding three new entities: pulmonary tuberculosis in over 12 's, recurrent bacterial pneumonia (two or more outbreaks during a 12 month period) and invasive cervical cancer associated with HPV. The most frequent diseases at the time of diagnosis were: disseminated or extra-pulmonary tuberculosis $(18 \%$ of the 2,872 diseases diagnosed), followed by pneumonia by Pneumocystis jirovecii (15.4\%) and pulmonary tuberculosis in over 12 's $(13.5 \%)$. Cervical cancer represented $1 \%$ of the frequent AIDS' associated diseases. Other pathologies included in the diagnosis of AIDS, in order of frequency, were esophageal candidiasis, Kaposi's sarcoma, Hodgkin's lymphoma, and extra-pulmonary cryptococcosis.

\section{AIDS and Immigrants}

Until 1998, the percentage of cases of AIDS in the NWS Register of AIDS in foreigners (individuals born outside of Spain but living in NWS) was below 2\%. In 1999, this percentage rose to $5.3 \%$ of all cases. However, a large increase occurred in 2005, with this percentage reaching $15.7 \%$. The accumulated number of patients from 1984 to 2008 was 127 out of the total of 3,766 registered cases, with 81 cases $(64 \%)$ being in males. Immigrants included in this study were mainly from Latin America (48\% of the cases; 33 men and 28 women), followed by Europe (32\%) and subSaharan Africa (15\%).

The most common means of transmission among immigrants was unprotected heterosexual practices ( $44 \%$ of the cases; 56 out of 127) and shared syringes among IDUs (29\%). European immigrants were most commonly infected by unsafe sexual behavior (27/41 cases), with homosexual and bisexual practices representing $17 \%$ of the cases.

\section{DISCUSSION}

Clearly, the profile of HIV infected patients has changed in recent years. In the past, the majority of infections were transmitted IDUs sharing materials. Transmitting HIV through the sexual route of infection is becoming increasingly common. This trend has been observed in Spain and the European Union. Similar to what we report for NWS, transmission through IDUs decreased in the United States from 2004 to 2007 [4-8]. Cases resulting from MSM have increased and have represented the most common transmission route for the last three years of the period, accounting for more cases than heterosexual practices and IDUs [9].

With respect to date of birth, patients born between 1960 and 1969 represented $56 \%$ of the accumulated cases. It is also interesting to note that most frequent age at diagnosis continues to rise and is presently 41years-old. This trend has been reported throughout Spain as well as in other countries.

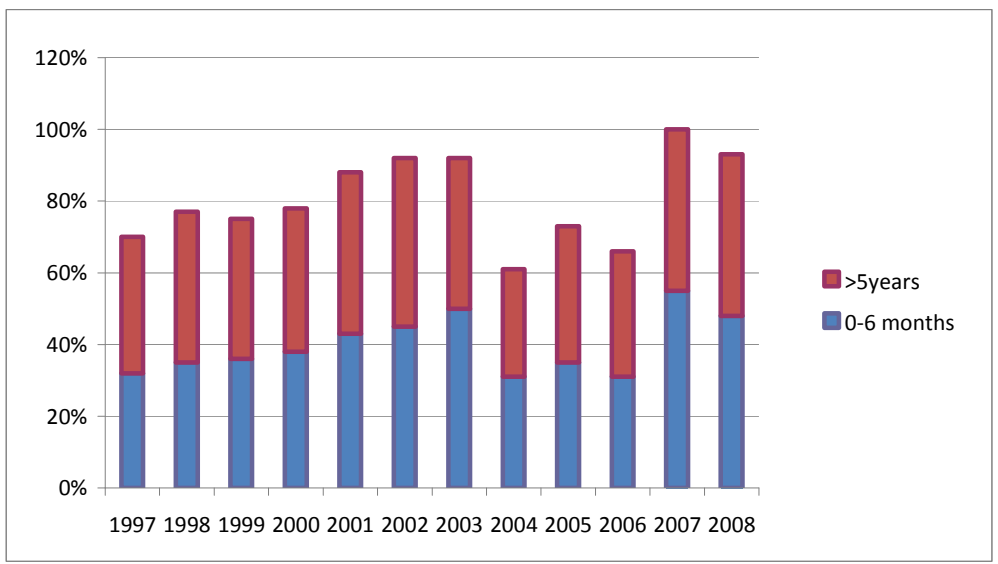

Fig. (5). Time between HIV (+) testing date and an AIDS diagnosis. 
Notably, we have recorded 66 cases of AIDS in persons over 65 years old. The majority of these cases were in males $(80 \%)$ and were mainly transmitted by the heterosexual route. We must therefore begin performing routine diagnostic tests for the early detection of HIV/AIDS in elderly patients requesting health care $[10,11]$.

The region of NWS has a strong record of HIV testing among childbearing women, although it is lower in private hospitals. Frequently, prenatal HIV testing is not documented in medical records and women are unaware of it. Improving prenatal care and tailoring these programs to specific populations, such as immigrants or marginalized groups, will result in a better understanding of HIV prevention and an increase in HIV testing before delivery [12, 13].

Patients infected with HIV but unaware of their diagnosis are of great concern to public health managers and clinics for various reasons. Because they do not receive highly effective antiretroviral treatment (HAART), their chances of developing and dying from AIDS greatly increase compared to patients treated at an earlier stage of disease [14]. Additionally, these patients can transmit the infection without realizing it. Our studies revealed that $54 \%$ of new infections were transmitted by the $25 \%$ of patients that were unaware of their infection status. In addition, the treatment and care cost for patients with late diagnoses is much greater than for patients diagnosed at an early stage $[15,16]$. For these reasons, detecting people infected with HIV who are unaware of their infection (constituting what is referred to as the "hidden epidemic") has become a priority in controlling HIV throughout the world.

In NWS, in the early years of the epidemic, the time interval between diagnosis with an HIV infection and diagnosis with AIDS was short. It was common for people to discover that they were infected with HIV at the same time that they were diagnosed with AIDS. Through the mid1990s, the proportion of people who were diagnosed with AIDS after knowing they were HIV+ for several years increased. Despite this improvement, there is still a significant proportion (over one-third) of people diagnosed of AIDS who are either unaware that they were infected with HIV or had only learned of their infection status within the previous six months. Notably, the percentage of people in this situation, in the NWS, reached 50\% in 2005 and 2006.

In the United States, it is estimated that around $25 \%$ of HIV infected persons are not aware of their status [17-20]. In China, the percentage is even higher [21]. Estimates have been published about the magnitude of this situation within the European Union, although many countries do not have complete information regarding it. Throughout the European Union, it is estimated that the percentage of undiagnosed $\mathrm{HIV}+$ people is $30 \%$, ranging from $15 \%$ (Norway) to more than $50 \%$ (Poland). In other countries of the European Region belonging to the WHO, the undiagnosed fraction may be as high as 65\% [22-29].

With respect to the diseases indicative of AIDS, we must comment on the period between 1994 to 2008. In 1994, the definition of AIDS was added to the epidemiological vigilance register, adding three new entities: pulmonary tuberculosis in people over the age of 12 , recurrent bacterial pneumonia (two outbreaks or more in a 12 month period) and invasive cervical cancer associated with HPV [30-32]. We have been working on this disease for many years. Squamous cell carcinoma is the most frequent histological type of HPV representing $90 \%$ of all vulvar and cervical primary neoplasias in HIV patients [33].

In Europe, the situation of immigrants varies by their country of origin. Immigrants from developing countries account for the majority of HIV-positive people in a number of developed countries. In the UK, heterosexual activity is now responsible for about half of all new HIV diagnoses with the majority of these with the majority of these newlyidentified individuals being of African origin [34]. Compared with people born in Portugal, African immigrants had a higher mortality rate for infectious diseases, including AIDS. There was considerable heterogeneity among Africans, with those from Cape Verde having the highest mortality. Death rates were more than five times higher among those who were unmarried compared to those who were. This result may be explained by a larger proportion of Africans being unmarried compared to non-African patients. Death rates were also higher among men who were manual workers compared to men who were not. Africans in Portugal fare worse than Africans in England and Wales, as death rates due to infectious disease and AIDS in Portugal are much higher [35].

Many male Tajik immigrant workers in Moscow have had unprotected sex with commercial sex workers. Although some of the immigrants have basic knowledge about HIV, their ability to protect themselves from acquiring HIV is compromised by harsh living and working conditions as a consequence of being unprotected by law in Russia [36].

Immigrants living in France represent 32\% of new infections and appear to be a target population for prevention [37].

Since 1996, the number of cases of AIDS in Italy has declined in the native Italian population. However, cases of foreign patients, including both recent immigrants and longterm residents, has increased from 3.9\% (in 1995 to 1996) to $15.4 \%$ (in 2001 to 2002) [38].

AIDS patients born outside of Spain and living in NWS account for $19 \%$ of the cases currently registered (29\% of women and $15 \%$ of men). However, the neighboring country of Portugal accounts for $85 \%$ of the HIV (+) patients from the combined group of all of the European immigrants. As a result of this increase in the immigrant population in Spain over recent years, we must diversify prevention programs and adapt them to Portuguese immigrants, a population that is especially vulnerable because it is highly heterogeneous both socially and culturally. This is especially true in the case of women, many of whom practice prostitution [39].

In summary, the prevention and the control of HIV infection among the immigrant community remains an important challenge. We should involve Family Physicians who must investigate risk practices, prevent new cases by educating uninfected persons, and monitor the evolution of 
the disease in infected patients while offering them support and comfort.

\section{CONCLUSIONS}

The annual incidence of AIDS cases in NWS has stabilized at fewer than 50 cases per one million inhabitants since the year 2001. Of the 3,766 accumulated cases, 2,085 $(55 \%)$ have resulted in death. Over recent years, we have observed an increase in incidence but a decrease in mortality.

Reducing the percentage of people that have not been diagnosis with HIV infection $(44 \%)$ is a priority for people responsible for the control of the epidemic in NWS. We must increase the perception of the risk of infection.

We should promote testing for HIV as a contribution to the individual right of the patient to obtain information on his or her health condition, with particular emphasis on:

- $\quad$ The general population, especially with respect to heterosexual transmission.

- $\quad$ Providing attention to people who are over the age of 40 and particularly over the age of 65 .

- European (especially Portuguese), Latin American and sub-Saharan African immigrants.

- $\quad$ Young people that suffer or are at risk of suffering from social exclusion.

\section{REFERENCES}

[1] Public Health Service (DXSP). AIDS cases reported to the Galician Register of AIDS (1984-2008). Santiago de Compostela: Public Health Papers 2008.

[2] Public Health Service (DXSP). Action Plan anti-HIV / AIDS in Galicia 2003-2006. Santiago de Compostela: Technical Public Health Papers (Number. 16) 2003.

[3] Galárraga O, Colchero MA, Wamai RG, Bertozzi SM. HIV prevention cost-effectiveness: a systematic review. BMC Public Health 2009; 9: S5.

[4] Centres for Disease Control and Prevention (CDC). HIV Infection among Injected-Drug Users- 34 States, 2004-2007. MMWR Morb Mortal Wkly Rep 2009; 58: 1291-5.

[5] Public Health Service (DXSP). Report on HIV / AIDS in Galicia. Santiago de Compostela: Technical Public Health Paper 2009.

[6] Toro C, Soriano V. Grupo Español de Estudio del VIH-2 y HTLV1/2. Human immunodeficiency virus type 2 and human T-cell lymphotropic virus type 1 and type 2 infections in Spain: an update. Enferm Infecc Microbiol Clin 2009; 27: 377-9.

[7] EPIVIH Study Group. New diagnoses of HIV infection in patients from a network of HIV diagnosis centers, 2003-2006. Madrid: National Epidemiology Centre 2008.

[8] Epidemiological surveillance of HIV in Spain. Evaluation of new HIV diagnoses in Spain from the case reporting systems of the CCAA. 2003-2007. Madrid: National Epidemiology Centre. Autonomic Information Systems for New HIV diagnosis 2008.

[9] Diaz A, Junquera ML, Esteban V, et al. STI Study Group and EPIVIH Group HIV/STI co-infection among men who have sex with men in Spain. Euro Surveill 2009; 14. pii: 19426.

[10] Mothe B, Perez I, Domingo P, et al. HIV-1 infection in subjects older than 70: a multicenter cross-sectional assessment in Catalonia, Spain. Curr HIV Res 2009; 7: 597-600.

[11] Smith RD, Delpech VC, Brown AE, Rice BD. HIV transmission and high rates of late diagnoses among adults aged 50 years and over. AIDS 2010; 24: 2109-15.

[12] Salihu HM, Stanley KM, Mbah AK, August EM, Alio AP, Marty PJ. Disparities in rates and trends of HIV/AIDS during pregnancy across the decade, 1998-2007. J Acquir Immune Defic Syndr 2010; 53: 223-30.

[13] de Ruiter A, Mercey D, Anderson J, et al. British HIV Association and Children's HIV Association guidelines for the management of
HIV infection in pregnant women 2008. HIV Med 2008; 9: 452502.

[14] Marton S, Reyes-Darias JA, Sánchez-Luque FJ, Romero-López C, Berzal-Herranz A. In vitro and ex vivo selection procedures for identifying potentially therapeutic DNA and RNA molecules. Molecules 2010; 15: 4610-38.

[15] Krentz H, Auld M, Gill M. The high cost of medical care for patients who present late (CD4 $<200$ cells/microL) with HIV infection. HIV Med 2004; 5: 93-8.

[16] Smith CJ, Phillips AN, Hill T, et al. United Kingdom Collaborative HIV Cohort Study Group. The rate of viral rebound after attainment of an HIV load $<50$ copies $/ \mathrm{mL}$ according to specific antiretroviral drugs in use: results from a multicenter cohort study. Infect Dis 2005; 192:1387-97.

[17] Marks G, Crepaz N, Senterfitt JW, Janssen RS. Meta-analysis of high-risk sexual behavior in persons aware and unaware they are infected with HIV in the United States: implications for HIV prevention programs. J Acquir Immune Defic Syndr 2005; 39: 44653.

[18] Marks G, Crepaz N, Janssen RS. Estimating sexual transmission of HIV from persons aware and unaware that they are infected with the virus in the USA. AIDS 2006; 20: 1447-50.

[19] Centers for Disease Control and Prevention (CDC). Expanded HIV testing and trends in diagnoses of HIV infection - District of Columbia, 2004-2008. MMWR Morb Mortal Wkly Rep 2010; 59: 737-41.

[20] Centers for Disease Control and Prevention (CDC). Missed opportunities for earlier diagnosis of HIV infection--South Carolina, 1997-2005. MMWR Morb Mortal Wkly Rep 2006; 55: 1269-72.

[21] Albrektsson M, Alm L, Tan X, Andersson R. HIV/AIDS awareness, attitudes and risk behavior among university students in Wuhan, China. Open AIDS J 2009; 3: 55-62.

[22] van de Laar MJ, Likatavicius G. HIV and AIDS in the European Union, 2008. Euro Surveill 2009; 14: 19422.

[23] WHO Regional Office for Europe and UNAIDS report on progress since the Dublin Declaration. Euro Surveill 2008; 13: 18981.

[24] Ministry of Health and Consumption. Multisectoral Plan against HIV / AIDS. Spain, 2008-2012. Madrid: Centre Publications 2008.

[25] Hamers F, Phillips A. Diagnosed and undiagnosed HIV-infected populations in Europe. HIV Med 2008; 9: 6-12.

[26] Mussini C, Manzardo C, Johnson M, et al. Late Presenter Investigators. Patients presenting with AIDS in the HAART era: a collaborative cohort analysis. AIDS 2008; 22: 2461-9.

[27] Lazarus JV, Jürgens R, Weait M, et al. Overcoming obstacles to late presentation for HIV infection in Europe. Enferm Infecc Microbiol Clin HIV Med 2010: 31: 89-95.

[28] Mykhalovskiy E, Brown G, Kort R. XVII International AIDS Conference: From Evidence to Action - Social, behavioural and economic science and policy and political science. J Int AIDS Soc 2009; 12: S5.

[29] Kouznetsov L, Kuznetsov AV, Ruzicka T, et al. Knowledge and attitude regarding human immunodeficiency virus/acquired immunodeficiency syndrome in dermatological outpatients. J Eur Acad Dermatol Venereol 2009; 23: 927-33.

[30] Dang T, Cavassini M. Late diagnoses of HIV infection in 2009 in Switzerland: towards a universal HIV testing? Rev Med Suisse 2009; 5: 727-31.

[31] Vilata Corell JJ, Rodríguez-Cerdeira C. Cutaneous-mucous manifestations of HIV infection. In: Vilata Corell JJ, Ed. Manual of Dermatology and Venereology: Text and Atlas. Madrid: Editorial Médica Panamericana 2008; pp. 695-712.

[32] Grant AD, Bansi L, Ainsworth J, et al. United Kingdom Collaborative HIV Cohort Study Group. Tuberculosis among people with HIV infection in the United Kingdom: opportunities for prevention? AIDS 2009; 23: 2507-15.

[33] Rodríguez-Cerdeira C, Chillón R, Díez-Moreno S, Guerra-Tapia A. Prevalence and genotypic identification of human papillomavirus infection in a population from northwestern Spain. Open Dermatol J 2009; 3: 18-21.

[34] Doyal L, Anderson J, Paparini S.'You are not yourself': exploring masculinities among heterosexual African men living with HIV in London. Soc Sci Med 2009; 68:1901-7.

[35] Williamson LM, Rosato M, Teyhan A, Santana P, Harding S. AIDS mortality in African migrants living in Portugal: evidence of large social inequalities. Sex Transm Infect 2009; 85: 427-31. 
[36] Weine S, Bahromov M, Mirzoev A. Unprotected Tajik male migrant workers in Moscow at risk for HIV/AIDS. J Immigr Minor Health 2008; 10: 461-8.

[37] Bouchaud O, Chérabi K. Caring for immigrants living with HIVAIDS in France. Rev Prat 2006; 56: 1005-10.

[38] Saracino A, El-Hamad I, Prato R, et al. SIMIT Study Group. Access to HAART in HIV-infected immigrants: a retrospective multicenter Italian study. AIDS Patient Care STDS 2005; 19: 599606.

[39] Caro-Murillo AM, Gutiérrez F, Manuel Ramos J, et al. CoRIS HIV infection in immigrants in Spain: Epidemiological characteristics and clinical presentation in the CoRIS Cohort (20042006). Enferm Infecc Microbiol Clin 2009; 27: 380-8.

(C) Rodríguez-Cerdeira et al.; Licensee Bentham Open.

This is an open access article licensed under the terms of the Creative Commons Attribution Non-Commercial License (http://creativecommons.org/licenses/by-nc/ $3.0 /$ ) which permits unrestricted, non-commercial use, distribution and reproduction in any medium, provided the work is properly cited. 